DOI: 10.1002/adsc.201((will be filled in by the editorial staff))

"This is the peer reviewed version of the following article: Adv. Synth. Catal. 2016, 358, 1602-1607, which has been published in final form at DOI: 10.1002/adsc.201500895|. This article may be used for non-commercial purposes in accordance with Wiley Terms and Conditions for Self-Archiving published at http://olabout.wiley.com/WileyCDA/Section/id-820227.html." 


\title{
Catalytic One-Pot Oxetane to Carbamate Conversions: Formal Synthesis of Drug Relevant Molecules
}

\author{
Wusheng Guo, ${ }^{\text {a }}$ Victor Laserna, ${ }^{\text {a }}$ Jeroen Rintjema ${ }^{\mathrm{a}}$ and Arjan W. Kleij ${ }^{\mathrm{a} \mathrm{b}^{*}}$ \\ a Institute of Chemical Research of Catalonia (ICIQ), Av. Països Catalans 16, 43007 - Tarragona, Spain \\ Fax: (+34)-977920823; phone: (+34)-977920247; e-mail: akleij@iciq.es \\ b Catalan Institute of Research and Advanced Studies (ICREA), Pg. Lluís Companys 23, 08010 - Barcelona, Spain
}

Received: \#\#\#

Supporting information for this article is available on the WWW under http://dx.doi.org/10.1002/adsc.2015\#\#\#

\begin{abstract}
Oxetanes are versatile building blocks in drugrelated synthesis to induce property-modulating effects. Whereas related oxiranes are widely used in coupling chemistry with carbon dioxide $\left(\mathrm{CO}_{2}\right)$ to afford value-added commodity chemicals, oxetanes $/ \mathrm{CO}_{2}$ couplings remain extremely limited despite the recent advances in the synthesis of these four-membered heterocycles. Here we report an effective one-pot three-component reaction (3CR) strategy for the coupling of (substituted) oxetanes, amines and $\mathrm{CO}_{2}$ to afford a variety of functionalized carbamates
\end{abstract}

with excellent chemo-selectivity and good yields. The process is mediated by an aluminium based catalysts under relatively mild conditions and the developed catalytic methodology can be applied to the formal synthesis of two pharmaceutically relevant carbamates with the $3 \mathrm{CR}$ being a key step.

Keywords: amines; carbamates; carbon dioxide; one-pot synthesis; oxetanes

\section{Introduction}

An upsurge in the use of oxetanes as molecular scaffolds is currently observed in various fields of chemical sciences. ${ }^{[1-4]}$ Key areas of investigation include their use as components of (biodegradable) polymers, ${ }^{[5-7]}$ as useful synthetic intermediates towards more complex structures ${ }^{[8-11]}$ and the incorporation of these low molecular weight motifs into drug-like molecules to attain improved physico-chemical behavior. $^{[3,12]}$ Also, oxetane rings are found in biologically relevant molecules such as taxol. ${ }^{[13]}$

We have become interested in the use of carbon dioxide as a carbon feedstock in organic synthesis thereby replacing fossil fuel based approaches. ${ }^{[14-17]} \mathrm{A}$ successful method for $\mathrm{CO}_{2}$ conversion relies on the use of coupling partners with a relative high free energy (thermodynamic feasibility) combined with an effective catalyst (kinetic feasibility) to mediate the transformation to value added organic molecules. Oxiranes have been often used as suitable reaction partners and their coupling products with $\mathrm{CO}_{2}$ are typically cyclic ${ }^{[18]}$ or polymeric organic carbonates. ${ }^{[19,20]}$ While the field of oxirane $/ \mathrm{CO}_{2}$ couplings has tremendously advanced over the years and resulted in highly active, selective and/or sustainable catalyst systems, the corresponding oxetane $/ \mathrm{CO}_{2}$ coupling reaction has seldom been studied and successfully accomplished..$^{[21-23]} \mathrm{We}$ recently reported a rather general method for the coupling of (functional) oxetanes and $\mathrm{CO}_{2}$ to produce their six-membered organic carbonates. ${ }^{[24]}$ In an effort to capitalize further on this chemistry with the aim to prepare more complex organic molecules with potential in pharmaceutical chemistry, we considered that in situ aminolysis of these carbonates could enable the construction of useful carbamates (Scheme 1). Generally, carbamates are highly interesting synthetic targets due to their wide application potential as important components of polyurethane polymers, ${ }^{[25]}$ agrochemicals $^{[26]}$ and pharma-ceuticals. ${ }^{[27]}$

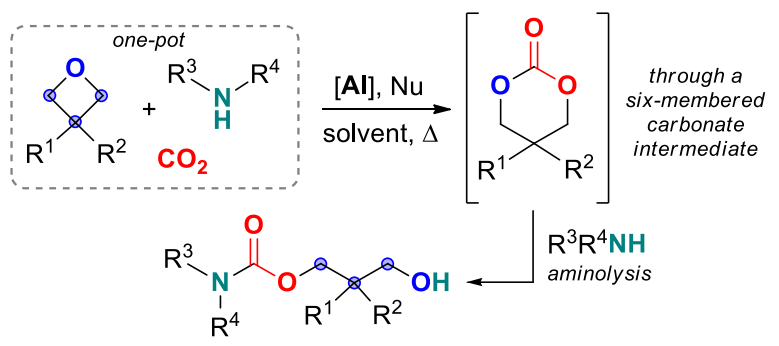

Scheme 1. Catalytic one-pot, modular approach towards oxetane-based carbamates.

The direct formation of carbamates from oxetanes, $\mathrm{CO}_{2}$ and amines is rather unexplored and we are aware of only one reported example based on the in situ formation of a carbamate nucleophile derived from an amine and $\mathrm{CO}_{2}$. Yoshida et al. described the formation of hydroxy-carbamates from simple oxetane (trimethylene oxide) and aliphatic primary or secondary amines: ${ }^{[28]}$ however, this non-catalytic approach suffers from many limitations due to the limited reactivity of the carbamate nucleophile. 
Among these limitations are the restricted scope in oxetanes (only two) and thus the eventual carbamate products that can be prepared, the harsh reaction conditions $\left(100-120^{\circ} \mathrm{C}, 40\right.$ bar) and long reaction times (up to $72 \mathrm{~h}$ ). Furthermore, the yields (most examples are $<31 \%$ ) of the hydroxy-carbamates were significantly compromised and competitive formation of amino-alcohols was noted which were actually found to be the major products. We envisioned that an efficient catalyst for the intermediate formation of a six-membered carbonate and in situ aminolysis could help to drastically improve the direct formation of carbamates from oxetanes, amines and $\mathrm{CO}_{2}$. This would amplify the scope of reaction partners and address the sustainability of the process by allowing lower temperature/pressure conditions for effective formation of the target carbamates. Previously we used such catalyst systems for highly efficient and demanding oxirane $/ \mathrm{CO}_{2}$ coupling reactions focusing on the formation of either cyclic $^{[29,30]}$ or polycarbonate structures. ${ }^{[31]}$

Here we describe a highly efficient methodology for the one-pot catalytic formation of functionalized carbamates from various (substituted) oxetanes, $\mathrm{CO}_{2}$ and primary/secondary amines in good yields. The applied Al-catalysis offers faster reactions, significantly reduced by-product formation and for the majority of the examples environmentally more benign reaction conditions $\left(70^{\circ} \mathrm{C}, 10\right.$ bar). The developed catalytic process towards these oxetanebased carbamates was also successfully applied towards the formal synthesis of Carisoprodol and the mono-carbamate of Felbatol, two carbamate-derived drug molecules.

\section{Results and Discussion}

We first examined simple oxetane as coupling partner towards carbamates using a 3CR approach (Experimental Section) having the amine already present at the start of the reaction. The amine reagent, present in stoichiometric amounts, could potentially coordinate to the catalyst thereby deactivating it and shut down catalytic turnover. However, in general Odonor ligands such as oxetanes have excellent coordination ability to main group metal complexes used herein and therefore we expected that the presence of the amine would only marginally affect the kinetics of the catalytic formation of the carbonate intermediate.

We previously described that six-membered carbonates can be efficiently prepared using an $\mathrm{Al}$ (III) aminotriphenolate complex having $t \mathrm{Bu}$ substituents on the periphery of the ligand and having an axial ligation site for oxetane activation. ${ }^{[2]}$ Thus, this complex was first probed in the coupling of oxetane, several amines and $\mathrm{CO}_{2}$ to afford their corresponding carbamate products 1-8 (Figure 1). These carbamates were produced in synthetically useful yields of up to $91 \%$ ( $c f$. ., synthesis of 6). However, we noted that for the formation of carbamates $2, \mathbf{4}, 5$ and 8 this one-pot strategy did not produce the desired carbamate in high yield. For instance, carbamate $\mathbf{2}$ was prepared only in a low yield of $35 \%$; we therefore modified the one-pot synthesis for $\mathbf{2}$ and added the amine at a later stage of the reaction (i.e., a sequential approach; Experimental Section) without isolating the carbonate intermediate. ${ }^{[32]}$ This afforded an appreciable increase in isolated yield (65\%) and apparently for some of the oxetane/amine combinations the formation of the intermediate six-membered carbonate (Scheme 1) was hampered; the much shorter total reaction time required for the sequential preparation of $\mathbf{2 , 4 , 5}$, and 8 $(16 \mathrm{~h})$ is support for this postulation. ${ }^{[33]}$

$$
\text { (AI]: } 0.5 \mathrm{~mol} \% ; \mathrm{TBAI} 2.5 \mathrm{~mol} \%
$$

Figure 1. Substrate scope investigated using oxetane (trimethylene oxide) as coupling partner: synthesis of carbamates 1-8. General conditions: [Al] is the $t \mathrm{Bu}$-derived $\mathrm{Al}(\mathrm{III})$ complex (see above), $4 \mathrm{mmol}$ scale, MEK $1.0 \mathrm{~mL}$, time/temperature indicated. TBAI/TBAB stands for tetrabutylammonium iodide/bromide. Note that for carbamates 2, 4, 5 and 8 the time indicated in brackets is a combination of (1) prior carbonate formation, and (2) subsequent aminolysis. All yields are of the isolated products after column purification. 
A variety of functionalities are readily introduced into these carbamates including pyridyl (1), cyclic amide (2), olefinic (4 and 6) and morpholinyl (5) groups. These results show that the one-pot approach is indeed feasible towards oxetane based carbamates and therefore we decided to extend the synthesis towards carbamates derived from various 3,3'disubsituted and 3-mono-substituted oxetanes.

Table 1. Screening study towards carbamate formation using 3,3'-dimethyloxetane, benzyl amine and $\mathrm{CO}_{2}$ as substrates. ${ }^{\text {[a] }}$

\begin{tabular}{|c|c|c|c|c|c|}
\hline Entry & Cat. & $\begin{array}{l}\text { Co-cat. } \\
{[\mathrm{mol} \%]}\end{array}$ & $\begin{array}{c}\mathrm{T} \\
{\left[{ }^{\circ} \mathrm{C}\right]}\end{array}$ & $\begin{array}{c}\mathrm{t} \\
{[\mathrm{h}]}\end{array}$ & $\begin{array}{c}\text { Yield of } \\
9 \\
{[\%]^{[\mathrm{c}]}}\end{array}$ \\
\hline 1 & - & - & 75 & 30 & 0 \\
\hline 2 & $\mathrm{Al}^{t \mathrm{Bu}}$ & - & 75 & 30 & 0 \\
\hline 3 & $\mathrm{Al}^{t \mathrm{Bu}}$ & - & 90 & 60 & 0 \\
\hline 4 & $\mathrm{Al}^{t \mathrm{Bu}}$ & PPNI 5 & 75 & 30 & 9 \\
\hline $5^{[\mathrm{b}]}$ & $\mathrm{Al}^{t \mathrm{Bu}}$ & TBAB 5 & 75 & 30 & 6 \\
\hline 6 & - & PPNI 5 & 75 & $18+10$ & 0 \\
\hline 7 & $\mathrm{Al}^{t \mathrm{Bu}}$ & $\begin{array}{c}\text { PPNI } \\
2.5\end{array}$ & 75 & $18+10$ & 50 \\
\hline $8^{[\mathrm{b}]}$ & $\mathrm{Al}^{t \mathrm{Bu}}$ & PPNI 5 & 60 & $18+10$ & 53 \\
\hline $9^{[\mathrm{b}]}$ & $\mathrm{Al}^{t \mathrm{Bu}}$ & PPNI 5 & 75 & $18+10$ & 71 \\
\hline 10 & $\mathrm{Al}^{t \mathrm{Bu}}$ & PPNI 5 & 90 & $18+10$ & $75^{[\mathrm{d}]}$ \\
\hline
\end{tabular}

[a] General conditions: $2.5 \mathrm{~mol} \%\left[\mathrm{Al}^{t \mathrm{Bu}}\right], 1.0 \mathrm{~mL}$ MEK, $p\left(\mathrm{CO}_{2}\right)^{\circ}=10$ bar. ${ }^{[b]} 3$ equiv of oxetane used. ${ }^{[c]}$ NMR yield using mesitylene as internal standard. ${ }^{[\mathrm{d}]}$ Isolated yield.

Before investigating this part of the substrate scope in more detail, we evaluated the feasibility of both the 3CR and sequential one-pot approach for a preselected combination of 3,3'-dimethyloxetane, benzyl amine and $\mathrm{CO}_{2}$ (see Table 1). In the absence of $\mathrm{Al}$ complex $\left(\mathrm{Al}^{t \mathrm{Bu}}\right)$ and/or nucleophile no conversion was observed (entries 1-3). ${ }^{[33]}$ The 3CR synthesis using both the Al-complex and PPNI (PPN = bistriphenylphosphine-iminium) only gave low yield of carbamate 9 (entries $4-5 ; \leq 9 \%$ ). Then the sequential approach was probed and the presence of only the nucleophile PPNI did not afford any product (entry 6), whereas the additional presence of $\mathrm{Al}^{\mathrm{tBu}}$ (entries 7-10) gave carbamate 9 in up to $75 \%$ yield after some further optimization of the reaction temperature and the catalyst/nucleophile ratio. The data obtained in these screening studies clearly show that for the more lethargic, substituted oxetanes ${ }^{[34]}$ the sequential approach towards carbamates is most appropriate.

To further substantiate the hypothesis that the lower reactivity of these substituted oxetanes is responsible for the low conversion noted in these cases with amine addition at the beginning of the one-pot approach, some further control experiments were carried out. When simple oxetane (i.e., trimethylene oxide) was treated with allyl amine using $\mathrm{Al}^{\mathrm{tBu}}$ as catalyst $(2.5$ $\mathrm{mol} \%)$, TBAB as nucleophile $(5 \mathrm{~mol} \%)$ at $75^{\circ} \mathrm{C}$ for 18 $\mathrm{h}$ in the absence of $\mathrm{CO}_{2}(c f$., synthesis of $\mathbf{4}$, Figure 1), full conversion was noted to the amino-alcohol product evidenced by ${ }^{1} \mathrm{H}$ NMR analysis. This result unambiguously demonstrates that for this combination of reaction partners the chemo-selectivity towards the carbamate $\mathbf{4}$ may be compromised due to competitive aminolysis of the oxetane substrate. The isolated yield of 4 was indeed significantly improved from 34 to $76 \%$ by addition of the amine at a later stage of the reaction (sequential approach) allowing first for six-membered carbonate formation avoiding amino-alcohol sideproducts.

We also subjected 3,3'-dimethyloxetane to similar reaction conditions described in entry 8 (Table 1) using benzyl amine and $5 \mathrm{~mol} \%$ of PPNI without adding $\mathrm{CO}_{2}$ and monitored possible conversion by ${ }^{1} \mathrm{H}$ NMR analysis. After $18 \mathrm{~h}$, only the starting materials could be detected and no amino-alcohol was thus formed. This latter result is in line with the lower reactivity of substituted oxetanes compared to parent oxetane. The observed lower carbamate yields when using substituted oxetanes through a 3CR approach is thus not related to competitive amino-alcohol formation as shown in the synthesis of $\mathbf{4}$.

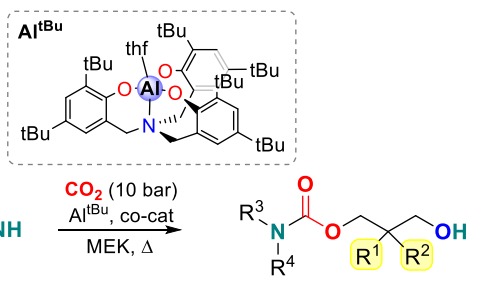

$$
\begin{aligned}
& \text { 10. Yield: } 64 \% ; 75^{\circ} \mathrm{C}, 18+10 \mathrm{~h} \\
& \text { [Al] } 2.5 \mathrm{~mol} \% ; \mathrm{PPNI} 5 \mathrm{~mol} \%
\end{aligned}
$$

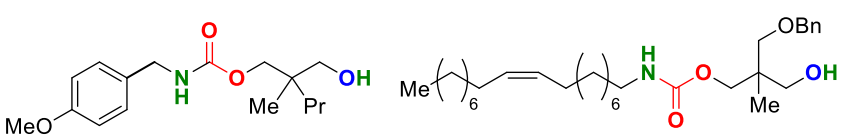

12. Yield: $57 \% ; 110^{\circ} \mathrm{C}, 40 \mathrm{bar}, 24+10 \mathrm{~h} \quad$ 13. Yield: $71 \% ; 75^{\circ} \mathrm{C}, 40 \mathrm{bar}, 24+10 \mathrm{~h}$ [Al] $2.5 \mathrm{~mol} \%$; PPNI $10 \mathrm{~mol} \% \quad$ [Al] 4 mol\%; TBAB $7 \mathrm{~mol} \%$

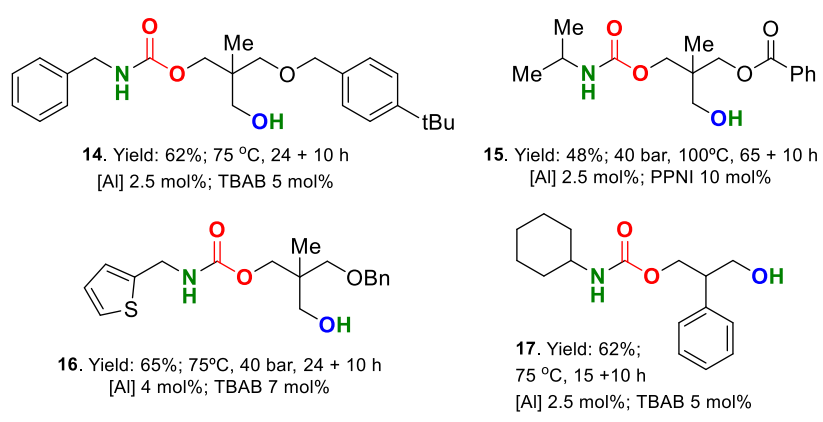

Figure 2. Investigated scope for substituted oxetanes: synthesis of carbamates 10-17. General conditions: [Al] is the $t \mathrm{Bu}$-derived $\mathrm{Al}$ (III) complex (see above), $4 \mathrm{mmol}$ scale, MEK $1.0 \mathrm{~mL}$, time/temperature indicated. TBAI/TBAB stands for tetrabutylammonium iodide/bromide, $\mathrm{PPN}=$ 
bis(triphenylphosphine)iminium. All yields are of the isolated products after column purification. 
The scope in oxetane partners was then amplified (see Figure 2) and various 3,3'-disubtituted substrates were subjected to the one-pot sequential approach to afford carbamates 10-17 in isolated yields of up to $71 \%$ ( $c f$., synthesis of 13). It should be noted that these conversions are highly challenging and therefore in some of the reported transformations higher reaction temperatures/pressures were unavoidable such as in the case of 12, 13, 15 and 16 . The conversion of substituted oxetanes greatly amplifies the opportunities in carbamate synthesis and highly functionalized scaffolds are accessible through this catalytic protocol; remarkably, the ester fragment in $\mathbf{1 5}$ was tolerated and this carbamate was isolated in $48 \%$ yield. Other useful groups such as a long-tail internal olefin (13) and 2-thiophenylyl (16) were also easily introduced.

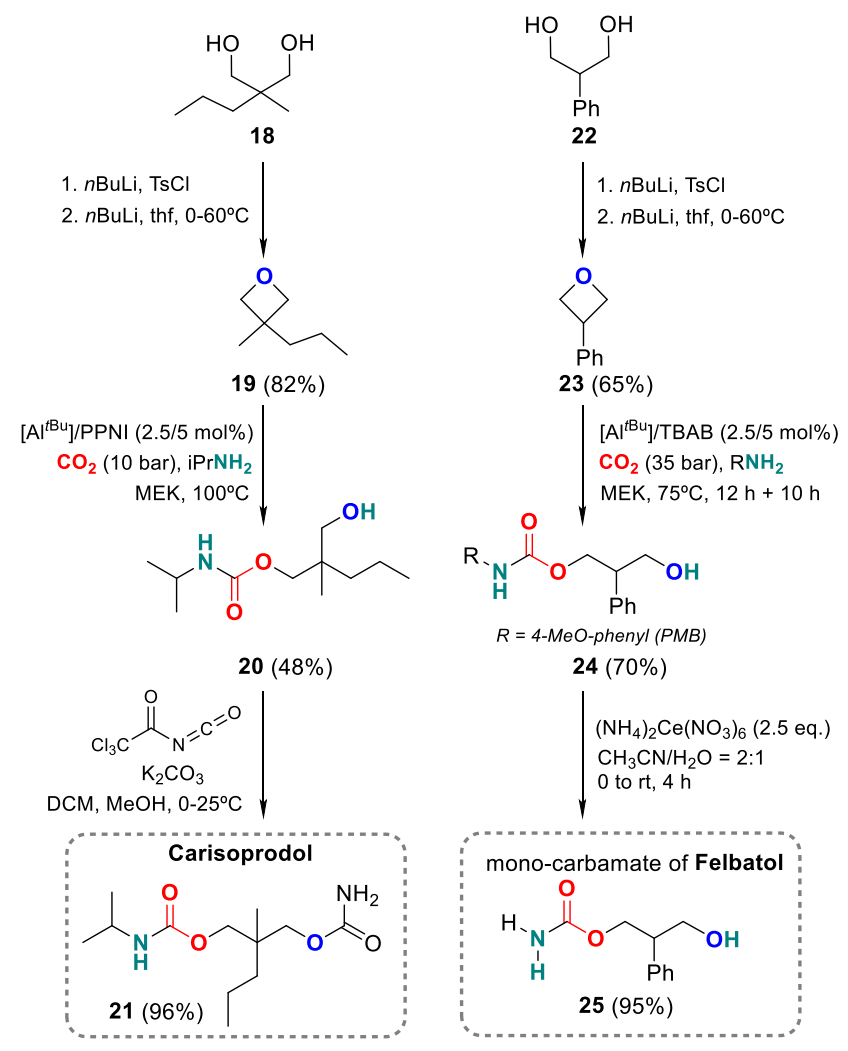

Scheme 2. Formal synthesis of Carisoprodol 21 and the mono-carbamate of Felbatol 25 using in the key step the Alcatalysed carbamate formation from an intermediate oxetane, amine and $\mathrm{CO}_{2}$.

The successful approach towards the oxetane based carbamates 1-17 prompted us to apply the newly developed catalytic process towards more relevant carbamate-based drug precursors including Carisoprodol (21) and the mono-carbamate of Felbatol (25), see Scheme 2. Both syntheses start of by using commercially available diols $\mathbf{1 8}$ and $\mathbf{2 2}$. These diols can be easily converted into their oxetane derivatives 19 and 23, respectively, by a known lithiation/tosylation-lithiation/cyclization sequence ${ }^{[35]}$ in appreciable yields. These oxetanes $\mathbf{1 9}$ and $\mathbf{2 3}$ then served as starting point for the catalytic one-pot carbamate formation reaction developed herein. The key hydroxy-carbamate intermediate $\mathbf{2 0}$ (48\% yield) was finally converted virtually quantitatively into Carisoprodol 21 by treatment with trichloroacetyl isocyanate. ${ }^{[36-38]}$ Carbamate $\mathbf{2 4}$, obtained in $70 \%$ yield from oxetane $\mathbf{2 3}$ using a similar catalytic carbamate formation as used for $\mathbf{2 0}$, was treated with ammonium cerium(IV)nitrate (CAN) to remove the 4-methoxybenzyl group $(\mathrm{PMB})^{[39]}$ and gave the hemi-carbamate 25 of Felbatol in $95 \%$ yield. For Carisoprodol, the original route ${ }^{[40]}$ is based on stepwise carbamation of 2-methyl-2-propyl-1,3-propanediol involving the use of phosgene or phosgene-derived dialkylcarbamate reagents. Thus, the newly developed protocol provides an alternative way of producing carbamate-derived pharmaceuticals using catalytic chemistry.

\section{Conclusion}

Summarising, we here describe a new catalytic method for the formation of highly functionalized carbamates using a one-pot methodology based on the threecomponent coupling between (substituted) oxetanes, primary/secondary amines and $\mathrm{CO}_{2}$ under effective Al-catalysis. This procedure does not require the isolation of the intermediate six-membered carbonates before aminolysis and greatly amplifies the scope towards these carbamate scaffolds.

The developed catalytic chemistry has also shown to be of use in the preparation of carbamate-derived drug molecules ( $c f$. synthesis of Carisoprodol and the hemi-carbamate of Felbatol) and thus provides an interesting new route towards pharmaceutically relevant molecules through challenging coupling chemistry that involves oxetanes and $\mathrm{CO}_{2}$. We believe that this approach may help to further capitalize on the application of oxetane building blocks in medicinal chemistry combined with the use of a renewable carbon feedstock $\left(\mathrm{CO}_{2}\right)$ and beyond.

\section{Experimental Section}

\section{Method A: 3CR synthesis of carbamates:}

The respective amine $(4.0 \mathrm{mmol}, 1$ eq. $)$, oxetane $(12 \mathrm{mmol}$, 3 eq.), Al-complex ( $\left.\mathrm{Al}^{\mathrm{tBu}}, 0.5-2 \%\right)$, TBAB/PPNCl and MEK (1 mL) were charged into a $30 \mathrm{~mL}$ stainless steel autoclave. The autoclave was then subjected to three cycles of pressurization and depressurization with carbon dioxide ( 5 bar), before final stabilization of the pressure at 10 bar. The autoclave was sealed and heated to $60-100^{\circ} \mathrm{C}$ and left stirring for the required time. Then the autoclave was cooled to r.t. and depressurized. After the reaction, the analytically pure carbamate product was isolated by flash chromatography. 
Method B: sequential synthesis of carbamates:

The respective oxetane $(4.0 \mathrm{mmol}, 1$ eq. $), \mathrm{Al}$-complex $\left(\mathrm{Al}^{t \mathrm{Bu}}\right.$, $0.5-2.5 \%)$, TBAB/PPNCl and MEK (1 mL) were charged into a $30 \mathrm{~mL}$ stainless steel autoclave. The autoclave was then subjected to three cycles of pressurization and depressurization with carbon dioxide ( 5 bar), before final stabilization of the pressure at 10 bar. The autoclave was sealed and heated to $75-110^{\circ} \mathrm{C}$ and left stirring for the required time. Then the autoclave was cooled to r.t. and depressurized. Hereafter, the respective amine (1.2 equiv for non-volatile amines and 3 equiv for volatile amines) was added into the reaction mixture and the autoclave was sealed and heated to $75-110^{\circ} \mathrm{C}$ for $10 \mathrm{~h}$. Finally, the autoclave was cooled down to room temperature again, and the analytically pure carbamate product was then isolated by flash chromatography.

\section{Synthesis of carbamate (6)}

The product was obtained through the 3CR approach using $1.5 \mathrm{~mol} \%\left[\mathrm{Al}^{\mathrm{BBu}}\right], 2.5 \mathrm{~mol} \%$ PPNI and performing the reaction at $70^{\circ} \mathrm{C}$ and $10 \mathrm{bar}$ for $60 \mathrm{~h}$. Carbamate $\mathbf{6}$ was isolated after column purification in $91 \%$ yield. Note: the product is unstable when kept in the presence of air. ${ }^{1} \mathrm{H}$ NMR (300 MHz, $\left.\mathrm{CDCl}_{3}\right): \delta=5.19(\mathrm{t}, J=6.5 \mathrm{~Hz}, 1 \mathrm{H}), 5.07$ $(\mathrm{t}, J=6.7 \mathrm{~Hz}, 1 \mathrm{H}), 4.61(\mathrm{br} \mathrm{s}, 1 \mathrm{H}), 4.24(\mathrm{~m}, 2 \mathrm{H}), 3.80-3.76$ $(\mathrm{m}, 2 \mathrm{H}), 3.67$ (s, 2H), 2.36 (br s, 1H), 2.12-1.97 (m, 4H), $1.83(\mathrm{~m}, 2 \mathrm{H}), 1.68(\mathrm{~s}, 3 \mathrm{H}), 1.66(\mathrm{~s}, 3 \mathrm{H}), 1.60(\mathrm{~s}, 3 \mathrm{H})$; ${ }^{13} \mathrm{C}\left\{{ }^{1} \mathrm{H}\right\}$ NMR $\left(101 \mathrm{MHz}, \mathrm{CDCl}_{3}\right): \delta=157.19,139.83$, 131.89, 123.92, 120.23, 61.66, 59.00, 58.97, 39.56, 32.44, $26.49,25.79,17.80,16.34$; IR (neat): $v=1688 \mathrm{~cm}^{-1}$ $(\mathrm{NC}(=\mathrm{O}) \mathrm{O}) ; \mathrm{HRMS}(\mathrm{ESI}): \mathrm{m} / z$ calcd. $278.1727(\mathrm{M}+\mathrm{Na})^{+}$, found: 278.1738 .

\section{Synthesis of carbamate (13)}

The product was obtained through the sequential approach using $4.0 \mathrm{~mol} \%\left[\mathrm{Al}^{t \mathrm{Bu}}\right], 7.0 \mathrm{~mol} \% \mathrm{PPNI}$ and performing the first step of the conversion at $75^{\circ} \mathrm{C}$ and 40 bar for $24 \mathrm{~h}$. The second step, after addition of the amine, was carried out at $75^{\circ} \mathrm{C}$ for $10 \mathrm{~h}$. The carbamate 13 was isolated after column purification in $71 \%$ yield. ${ }^{1} \mathrm{H}$ NMR $\left(500 \mathrm{MHz}, \mathrm{CDCl}_{3}\right): \delta=$ $7.36-7.28(\mathrm{~m}, 5 \mathrm{H}), 5.37-5.35(\mathrm{~m}, 2 \mathrm{H}), 4.70(\mathrm{br} \mathrm{s}, 1 \mathrm{H}), 4.70$ (s, 2H), 4.12-4.05 (m, 2H), $3.44(\mathrm{~m}, 2 \mathrm{H}), 3.38-3.37$ (m, 2H), $3.18-3.14(\mathrm{~m}, 2 \mathrm{H}), 3.04$ (br s, $1 \mathrm{H}), 2.06-1.96(\mathrm{~m}, 4 \mathrm{H}), 1.48$ $(\mathrm{m}, 2 \mathrm{H}), 1.32-1.26(\mathrm{~m}, 22 \mathrm{H}), 0.91(\mathrm{~s}, 3 \mathrm{H}), 0.89-0.87(\mathrm{~m}$, $3 \mathrm{H}) ;{ }^{13} \mathrm{C}\left\{{ }^{1} \mathrm{H}\right\}$ NMR (101 MHz, $\left.\mathrm{CDCl}_{3}\right): \delta=157.30,138.28$, 130.11, 129.90, 128.51, 127.76, 127.61, 81.91, 74.54, 73.66, $66.65,66.50,41.27,41.08,29.90,29.87,29.83,29.65,29.45$, $29.39,27.35,27.32,26.87,23.83,17.26,14.25$; IR (neat): $v$ $=1699 \mathrm{~cm}^{-1}(\mathrm{NC}(=\mathrm{O}) \mathrm{O}) ;$ HRMS $(\mathrm{ESI}): \mathrm{m} / \mathrm{z}$ calcd. 526.3867 $(\mathrm{M}+\mathrm{Na})^{+}$, found: 526.3859 .

For the experimental details and analytical data of all other carbamates, and copies of relevant NMR/IR spectra see the Supporting Information.

\section{Acknowledgements}

We thank ICIQ, ICREA, and the Spanish Ministerio de Economía y Competitividad (MINECO) through project CTQ2014-60419-R, and support through Severo Ochoa Excellence Accreditation 2014-2018 (SEV-2013-0319). WG thanks the Cellex Foundation for supporting his postdoctoral fellowship and VL thanks the Generalitat de Catalunya for a FI pre-doctoral fellowship. Dr. Marta Giminez and Cristina Rivero are thanked for their help regarding the high-pressure experiments.

\section{References}

[1] O. A. Davis, J. A. Bull, SynLett. 2015, 26, A-F.
[2] G. Wuitschik, E. M. Carreira, B. Wagner, H. Fischer, I. Parrilla, F. Schuler, M. Rogers-Evans, K. Müller, J. Med. Chem. 2010, 53, 3227.

[3] J. A. Burkhard, G. Wuitschik, M. Rogers-Evans, K. Müller, E. M. Carreira, Angew. Chem. Int. Ed. 2010, 49,9052 .

[4] M. D’Auria, R. Racioppi, Molecules 2013, 18, 11384.

[5] D. J. Darensbourg, A. I. Moncada, W. Choi, J. H. Reibenspies, J. Am. Chem. Soc. 2008, 130, 6523.

[6] M. Helou, O. Miserque, J.-M. Brusson, J.-F. Carpentier, S. M. Guillaume, Chem. Eur. J. 2010, 16, 13805.

[7] B. Schulte, C. A. Dannenberg, H. Keul, M. J. Möller, J. Polym. Sci., Part A: Polym. Chem. 2013, 51, 1243.

[8] M. McLaughlin, R. Yazaki, T. C. Fessard, E. M. Carreira, Org. Lett. 2014, 16, 4070.

[9] P. B. Brady, E. M. Carreira, Org. Lett. 2015, 17, 3350.

[10] K. F. Morgan, I. A. Hollingsworth and J. A. Bull, Chem. Commun., 2014, 50, 5203.

[11] C. A. Malapit, A. R. Howell, J. Org. Chem. 2015, 80, 8489.

[12] A. F. Stepan, K. Karki, W. S. McDonald, P. H. Dorff, J. K. Dutra, K. J. DiRico, A. Won, C. Subramanyam, I. V. Efremov, C. J. O’Donnell, C. E. Nolan, S. L. Becker, L. R. Pustilnik, B. Sneed, H. Sun, Y. Lu, A. E. Robshaw, D. Riddell, T. J. O’Sullivan, E. Sibley, S. Capetta, K. Atchison, A. J. Hallgren, E. Miller, A. Wood, R. S. Obach, J. Med. Chem. 2011, 54, 7772.

[13] M. C. Wani, H. L. Taylor, M. E. Wall, P. Caggon and A. T. McPhall, J. Am. Chem. Soc. 1971, 93, 2325.

[14] M. Cokoja, C. Bruckmeier, B. Rieger, W. A. Herrmann, F. E. Kühn, Angew. Chem. Int. Ed. 2011 , 50,8510 .

[15] M. Aresta, A. Dibenedetto, A. Angelini, Chem. Rev. 2014, 114, 1709.

[16] C. J. Whiteoak, N. Kielland, A. W. Kleij, Adv. Synth. Catal. 2013, 355, 2115.

[17] M. Peters, B. Köhler, W. Kuckshinrichs, W. Leitner, P. Markewitz, T. E. Müller, ChemSusChem 2011, 4, 1216.

[18] C. Martín, G. Fiorani, A. W. Kleij, ACS Catal. 2015, 5,1353

[19] M. Taherimehr, P. P. Pescarmona, J. Appl. Polym. Sci. 2014, 131, 41141.

[20] X.-B. Lu, D. J. Darensbourg, Chem. Soc. Rev. 2012, 41,1462 .

[21] B. R. Buckley, A. P. Patel, K. G. Upul Wijayantha, Eur. J. Org. Chem. 2015, 474.

[22] D. J. Darensbourg, A. Horn, Jr, A. I. Moncada, Green Chem. 2010, 12, 1376.

[23] D. J. Darensbourg, A. I. Moncada, Macromolecules 2010, 43, 5996. 
[24] J. Rintjema, W. Guo, E. Martin, E. C. Escudero-Adán, A. W. Kleij, Chem. Eur. J. 2015, 21, 10754.

[25] H.-W. Engels, H.-G. Pirkl, R. Albers, R. W. Albach, J. Krause, A. Hoffmann, H. Casselmann, J. Dormish, Angew. Chem. Int. Ed. 2013, 52, 9422.

[26] T. R. Fukuto, Environ. Health Perspect. 1990, 87, 245.

[27] A. K. Ghosh, M. Brindisi, J. Med. Chem. 2015, 58, 2895.

[28] S. Ishii, M. Zhou, Y. Yoshida, H. Noguchi, Synth. Commun. 1999, 29, 3207.

[29] V. Laserna, G. Fiorani, C. J. Whiteoak, E. Martin, E. C. Escudero-Adán, A. W. Kleij, Angew. Chem. Int. Ed. 2014, 53, 10416.

[30] C. J. Whiteoak, N. Kielland, V. Laserna, E. C. Escudero-Adán, E. Martin, A. W. Kleij, J. Am. Chem. Soc. 2013, 135, 1228.

[31] L. Peña Carrodeguas, J. González-Fabra, F. CastroGómez, C. Bo, A. W. Kleij, Chem. Eur. J. 2015, 21, 6115.

[32] Conditions used in this approach: $2.5 \mathrm{~mol} \%\left[\mathrm{Al}^{t \mathrm{Bu}}\right], 5.0$ $\mathrm{mol} \% \mathrm{TBAB}, 75^{\circ} \mathrm{C}, 10 \mathrm{bar}$.

[33] Please note that $\mathrm{CO}_{2}$ and alkyl amines may give rise to carbamate nucleophiles themselves. However, when we carried out the synthesis of compound 7 (Figure 1) based on the simplest oxetane in the absence of TBAI, we found only amino alcohol product $(7 \%$ yield by
NMR; mesitylene as internal standard) with traces of the carbamate product 7 . Note that carbamate formation in the absence of an external nucleophile using 3,3'-dimethyloxirane (Table 1, entries 2 and 3) does not lead to any product formation. This clearly demonstrates that carbamate nucleophiles possibly derived from amines and $\mathrm{CO}_{2}$ are incompetent towards oxetane ring-opening under the reaction conditions used.

[34] Note that Darensbourg et al. also observed that 3,3'substituted oxetanes show much slower kinetics in their coupling with $\mathrm{CO}_{2}$, see: D. J. Darensbourg, A. I. Moncada, S.-H. Wei, Macromolecules 2011, 44, 2568.

[35] P. Picard, D. Leclercq, J.-P. Bats, J. Moulines, Synthesis 1981, 550.

[36] P. A. Hedin, R. C. Gueldner, A. C. Thompson, Anal. Chem. 1970, 42, 403.

[37] Y. Ichikawa, M. Osada, I. I. Ohtani, M. Isobe, J. Chem. Soc., Perkin Trans. 1 1997, 1449.

[38] P. Kocovsky, Tetrahedron Lett. 1986, 27, 5521.

[39] H. Adams, J. C. Anderson, S. Peace, A. M. K. Pennell, J. Org. Chem. 1998, 63, 9932.

[40] F. M. Berger, B. J. Ludwig, U.S. Patent No. 2937119; Chem. Abstr. 1960, 54, 18367. 


\section{FULL PAPER}

Catalytic One-Pot Oxetane to Carbamate

Conversions: Formal Synthesis of Drug Relevant

Molecules

Adv. Synth. Catal. 2015, 357, Page - Page

Wusheng Guo, Victor Laserna, Jeroen Rintjema and Arjan W. Kleij*

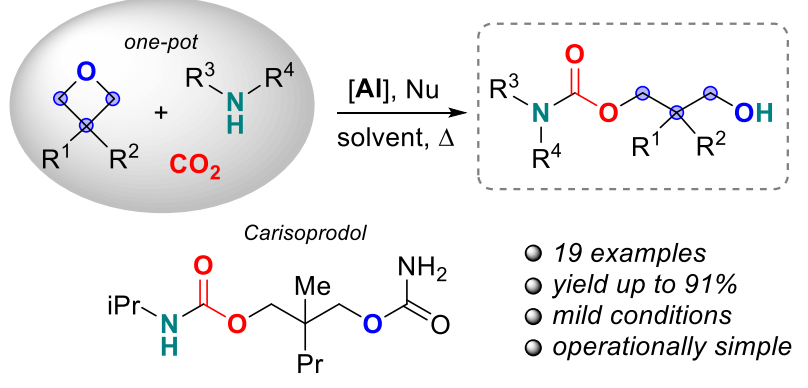

